Journal of Environmental Science and Public Health

doi: 10.26502/JESPH.004

Volume 1, Issue 1

Case Report

\title{
Mind What You Put in a Furnace: A Case Study for a Laboratory Incident
}

\author{
Emad Yousif*, Wedad H. Al-Dahhan, Ali Abd Ali, Alaa Adnan Rashad, and Evon Akram
}

Department of Chemistry, College of Science, Al-Nahrain University, Baghdad, Iraq

*Corresponding Author: Emad Yousif, Department of Chemistry, College of Science, Al-Nahrain University, Baghdad, Iraq, Tel: +964-7705839300; E-mail: emadayousif@gmail.com

Received: 12 June 2017; Accepted: 05 July 2017; Published: 13 July 2017

\begin{abstract}
There is no doubt that laboratories are extremely dangerous places as many hazardous materials are dealt with. It is mandatory to take safety precautions in laboratories at all times with no excuses. Herein, we report an incident took place in a research laboratory at Department of Chemistry Al-Nahrain University as a result of dealing with some chemicals without knowing their risks in advance. We emphasize the importance of having all necessary information of the chemical that we wish to deal with, including the safety data sheet (SDS) and based on that we can make the risk assessment form. Also, we would like to recommend adding good and functional smoke detectors as well as some oxygen sensors to ensure safe working area.
\end{abstract}

Keywords: Hazardous materials; Risk assessment; SDS; Toxic

\section{Introduction}

To avoid any risk arises from dealing with chemicals, it is customary that researchers refer to the SDS and prepare a risk assessment data sheet in compliance with the hazard of the chemical to be used [1-3]. As a general rule, every chemical used in the laboratory must be considered as a hazardous material and safety precautions must be taken into accounts. Additionally, sufficient information must be obtained about all chemicals in the inventory of all laboratories [4-9]. However, the story was different in one of our laboratories as there was an accident took place as a result of unknown chemicals were put in a furnace and heated to $400^{\circ} \mathrm{C}$ upon request from a postgraduate student. The student did not give any information about these chemicals to the person who was in charge of that laboratory. Consequently, under this elevated temperature, all chemicals were charred with evolving some toxic fumes. The 
student confirmed earlier that these materials are completely safe and they are absolutely stable at high temperatures as he did some thermal treatments before without any problems. Nevertheless, the toxic fumes produced from the furnace upon heating to $400^{\circ} \mathrm{C}$ (as depicted in Figure 1) were raising the alarm of a serious danger.

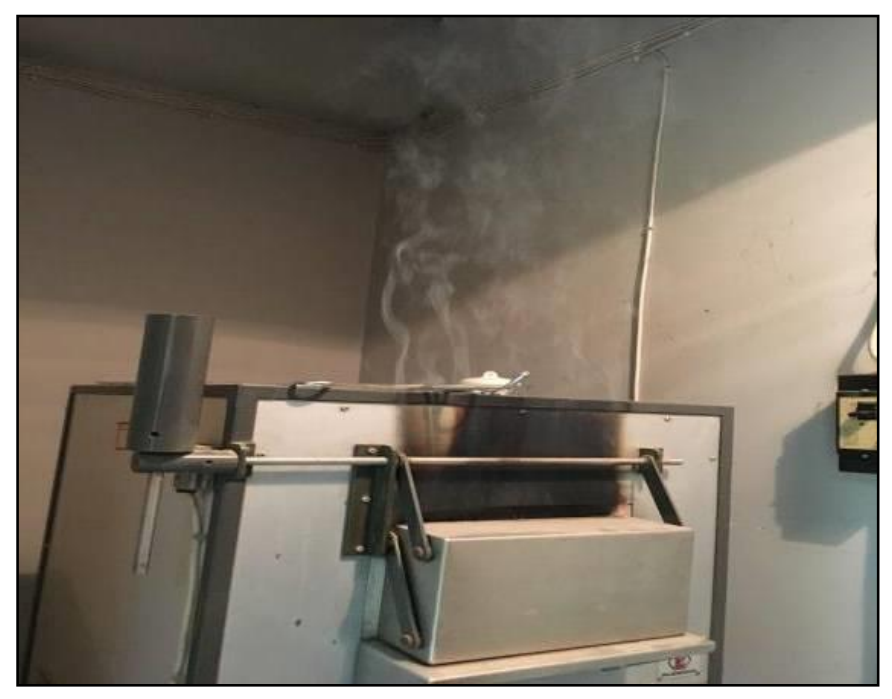

Figure 1: Unknown chemicals inside the furnace at $400^{\circ} \mathrm{C}$ generating toxic fumes.

The laboratory manager once he observed these fumes, he turned the furnace off and unplugged it from the main electricity supplier. Thereafter he notified everyone in the laboratory and told them to evacuate the building immediately using the emergency exit as shown in Figure 2.

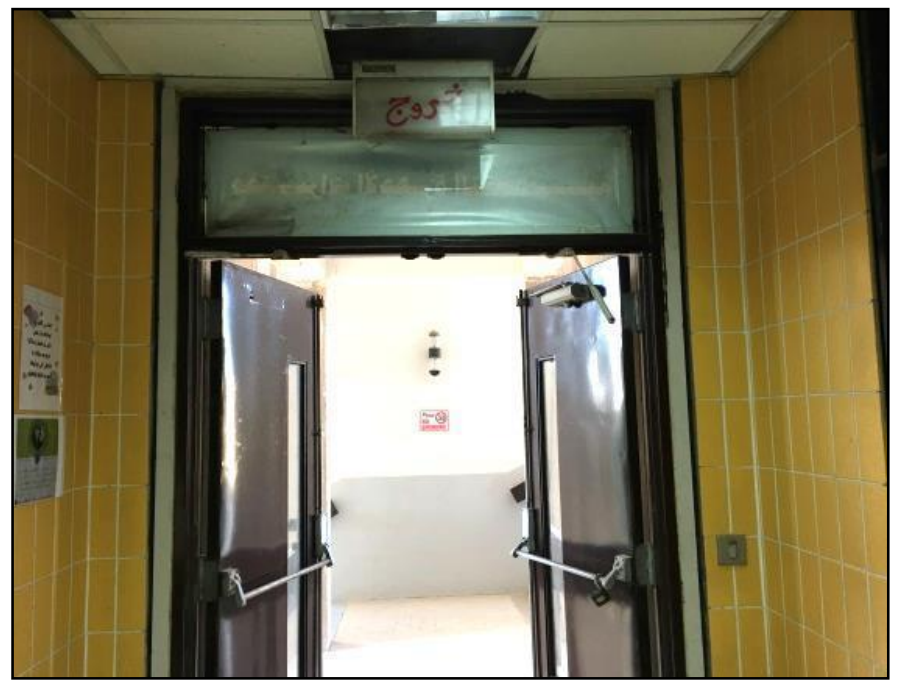

Figure 2: Opening the door of the emergency exit for evacuation.

After exactly two hours, the furnace was opened by the laboratory manager and left opens for three hours to allow all fumes to come out with offering more ventilation of these toxic fumes. The crucibles were removed from the 
furnace safely and it was totally clear that all chemicals in these crucibles were charred as shown in Figure $3 \mathrm{~A}$ and 3B.

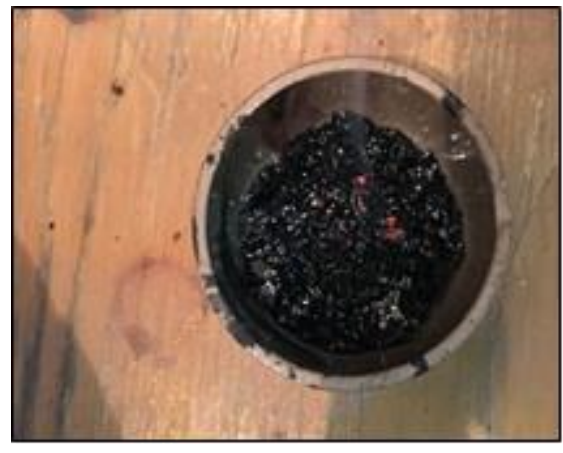

Figure 3A: The crucible with ongoing burned chemicals in.

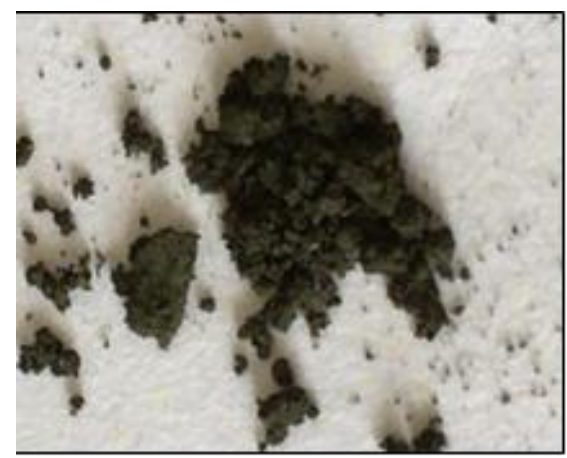

Figure 3B: The chemicals after complete burning.

The student was questioned about the nature of these chemicals and he mentioned the following information that are displayed in Table 1.

\begin{tabular}{|l|l|}
\hline Chemicals & Quantity \\
\hline Nickel (II) nitrate hexahydrate & $0.07 \mathrm{~g}$ \\
\hline Chromium nitrate Nonahydrate & $3.90 \mathrm{~g}$ \\
\hline Polyvinyl alcohol & $8.00 \mathrm{~g}$ \\
\hline
\end{tabular}

Table 1: Information given by the student regarding the chemicals.

\section{Hazards Expected From Using the Above Chemicals}

It is customary to refer to SDS of any chemical prior to use it. However, we doubt that the student has no idea of the SDS of these chemicals and that is completely unsafe.

That is why we thought it must be noted that SDS is very important document and all chemists must refer to it before conducting any chemical reaction or treatment. The SDS of chromium nitrate says that it thermally decomposes at $100^{\circ} \mathrm{C}$ which is much less that the furnace temperature $\left(400^{\circ} \mathrm{C}\right)$. This means that the chromium nitrate was completely burnt at this temperature. Now, let us see whether the chromium nitrate at this temperature is going to be inert or reactive if mixed with other combustible materials or not. Based on the SDS and the fire diamond of polyvinyl alcohol, it has got 2 score of flammability, which means it must reasonably heated. Otherwise, at $400^{\circ} \mathrm{C}$ it is highly flammable. This is exactly what happened when mixed with the chromium nitrate which in turn was very reactive with the flammable material (polyvinyl alcohol) and generated toxic fumes. 


\section{Lessons Learned from This Incident}

In the light of the present case study, the following lessons were learnt:

- It is mandatory to all researchers, students, and workers in any chemical laboratory to carefully read the SDS before performing any experiment. Especially, when it comes to thermal treatment of chemicals as it is extremely dangerous to use elevated temperatures with highly combustible materials.

- Giving all available information about chemicals which are to be thermally treated.

- Providing all necessary personal protective equipment (PPE) in all laboratories and using them appropriately.

\section{Recommendations}

- There should not be any chemical reaction or treatment done in laboratory without reading and understanding the SDS and preparing a risk assessment data sheet signed and approved by safety officer in that research unit. The risk assessment must include the chemical, type of hazard, risk score, and suggested ways to control risk and minimize the occurrence of any incident.

- Relocating the furnace to a different place which offers more space and better ventilation.

- There must be a smoke detector mounted in every laboratory which alarm people in case of any fire. As a matter of fact, there is a fire alarm system within the building, but unfortunately, it is inactive for unknown reasons. However, we believe that mounting some smoke detectors in every laboratory will assist in minimizing any risk to people or amenities.

- We recommend mounting an oxygen sensor in the same laboratory where the furnace is located and that will guarantee a sufficient amount of oxygen to people who are working in this facility.

- It is good to have an emergency exit, but also there must be an assembly area located in a safe place and away from any potential danger. Otherwise, people will evacuate building, but they might still nearby the hazard of being injured. That is why; we strongly recommend allocating an assembly area for people who have been evacuated.

\section{Conclusion}

To conclude, there must be a clear idea about all chemicals to be treated or used for reactions. This will guarantee a safe working environment for all people who working within any laboratory. Additionally, it is mandatory to install some technical equipment which we believe they are necessary for maintaining safety and minimizing the hazard of any incident.

\section{Acknowledgments}

We would like to express our deep thank to Department of Chemistry, College of Science, Al-Nahrain University for helping in making this case study.

\section{Conflicts of Interests}

The authors declare no conflict of interest. 


\section{References}

1. Ali A, Al-Dahhan W, Zageer D, et al. A Vision to Promote the Forensic DNA Facility at Al-Nahrain University in Terms of Safety Measures. Oriental Journal of Physical Sciences 2 (2017): 37-41.

2. Ali A, Shaalan N, Al-Dahhan W, et al. For a Safer Working Environment with Hydrofluoric Acid in Iraqi Industrial Plants. Open Journal of Safety Science and Technology 6 (2016): 77-80.

3. Al-Zuhairi A, Al-Dahhan W, Hussein F, et al. Teaching Laboratory Renovation. Oriental Journal of Physical Sciences 1 (2016): 31-35.

4. Yousif E, Al-Dahhan W, Abed R, et al. Improvement of A Chemical Storage Room Ventilation System. Journal of Progressive Research in Chemistry 4 (2016): 206-210.

5. Ali A, Shaalan N, Al-Dahhan W, et al. A Technical Evaluation of a Chemistry Laboratory: A Step Forward for Maintaining Safety Measures. Oriental Journal of Physical Sciences 2 (2017): 68-71.

6. Rasool R, Al-Dahhan W, Al-Zuhairi A, et al. Fire and Explosion Hazards Expected in a Laboratory. Journal of Laboratory Chemical Education 4 (2016): 35-37.

7. Wedad H, Al-Dahhan W, Al-Zuhairi A, et al. Laboratory biological safety cabinet (BSC) explosion. Karbala International Journal of Modern Science 2 (2016): 276-279.

8. Hussein F, Al-Dahhan W, Al-Zuhairi A, et al. Maintenance and Testing of Fume Cupboard. Open Journal of Safety Science and Technology 7 (2017): 69-75.

9. Ibrahim A, Yousif E, ALShukry A, et al. Hazard Analysis and Critical Control Point HACCP System. Iraqi National Journal of Chemistry 16 (2016): 172-185.

(C) 1 This article is an open access article distributed under the terms and conditions of the Creative 